\title{
Formation of Students' Written Russian Speech Skills in Organizing a Compound Sentence
}

\author{
Alan Tskhovrebov ${ }^{1, *}$ Tamara Magomedova ${ }^{2}$ \\ ${ }^{1}$ Military Institute (Engineering and Technical) of Military Academy of Material and Technical Support named \\ after General A.V. Khrulev of the Ministry of Defense of the Russian Federation, Saint Petersburg, Russian \\ Federation \\ ${ }^{2}$ Dagestan State University, Makhachkala, Russian Federation \\ *Corresponding author.Email: alanec1985@mail.ru
}

\begin{abstract}
The article deals with the organization of the teaching methods for formation of written speech skills in creating a compound sentence of students for whom Russian is not a native language. The paper reflects the experimental testing of a scientifically-based set of exercises designed for teaching a formation of a compound sentence, which allows improving the quality of Russian language teaching in a non-linguistic university. In the course of the work, it was found that the proposed method lets not only form skills in the grammatical aspect of the Russian language (in formation of a compound sentence), but also contributes to the development of stylistic skills in general. The study is essential, since the expression of various intentions through a compound sentence is important at the very beginning of learning a foreign (non-native) language. The proposed methodological system makes it possible to form stable skills of producing these syntactic constructions in oral and written speech.
\end{abstract}

Keywords: Russian language, Teaching methods, Compound sentence, Stylistic aspect, A set of exercises, Experimental testing.

\section{INTRODUCTION}

The problem of teaching Russian as a nonnative language remains relevant in linguistic methodology. A Russian language teacher should look for new ways to improve the learning process, since effective organization of training is very important for the success of the formation of Russian-language competence. To achieve this, in classes new forms of learning should be used, "which allow to achieve high performance in a short period of time and contribute to the intensification of the educational process" [1].

The research task is to design a scientifically based and experimentally tested set of exercises for a compound sentence, which will improve the quality of training and lead "to a high level of formation of the Russian-language professional communicative competence of students" [2]. According to the concept, proposed by E. I. Passov, "the formation of skills takes place in conditions adequate to speech" [3]. The author distinguishes the following set of exercises, the sequence of which is determined by the stages of the formation of speech skills: a) imitative, which involve work on speech models; b) substitutional, which include exercises characterized by the substitution of lexical units in the speech sample; c) transformational, which involve the transformation of the teacher's replica, that is, change the structure of the studied unit (structure); d) reproductiveindependent reproduction of the studied material [3]. As N. F. Koryakovtseva notes, "Reproductive activity is characterized by a focus on getting a desired ready-made result based on a sample using stereotypical methods" [4] 


\section{EXPERIMENTAL MODEL OF TEACHING THE ORGANIZATION OF A COMPOUND SENTENCE AS AN EFFECTIVE METHODICAL SYSTEM OF FORMATION OF COMMUNICATION SKILLS}

\subsection{Stylistic Level of Compound Sentence Analysis}

We can consider the most productive forms of tasks for formation skills in creating a compound sentence in the process of mastering the Russian language. A significant role in the development of students' speech and increasing the level of its culture, in our opinion, is played by stylistic exercises of the studied structures, aimed at developing the stylistic skills of students and aimed at forming the students' ability to create their own text of a certain style using the syntactic units considered in it.

In the work on the stylistics of a compound sentence, a significant place in our training system is occupied by analytical exercises, including tasks for analyzing texts related to different functional and semantic types of speech, as well as synthetic exercises aimed at developing the ability to build a statement in a certain logical sequence, to connect individual thoughts into a single coherent text.

The following standard tasks and questions are given to the texts:

- Title the text. Explain why you have chosen this title?

- Retell the text concisely.

- What functional and semantic type of speech does this text belong to (narrative, description, reasoning)? Explain your opinion.

- Define the text style.

- What grammatical means indicate this type of text? How does this relate to the style features?

- Which sentences predominate in this type of text (simple, compound, complex, asyndetic, multi-structural)?

- Give a description of all compound sentences, prove the correctness of your solution. Determine the semantic relations between the parts of compound sentences.

- Break the proposed text into complete semantic segments.
- Write your short essay-review on this text.

Here is an example of a text for analysis:

"The Word about Igor's regiment" takes only a few pages of an ancient manuscript, but for two centuries the people of Russia, torn by princely strife and nomad attacks, remembered it, quoted wise patriotic lines by heart.

By the time of the campaign of Igor, who secretly led the squads to the Dune and inadvertently lost his army and the honor of the commander, Russia broke up into several independent principalities. The feuds of the princes turned into bloody wars, and the nomadic tribes of the Polovtsians, who constantly raided the Russian lands, cut the ancient path from the Varangians to the Greeks and disrupted the economic ties of Russia with the southern and eastern lands. Their raids were accompanied by the destruction of cities and the capture of the inhabitants, but the princes, who had lost their sense of patriotism, were unable to deal a decisive blow to the Polovtsians because of the continuous rivalry.

Chroniclers, as a rule, only recorded events, and only some of them dared to give the assessment of individual actions of princes. But none of the Old Russian scribes rose to the height of wise historical generalizations. Only the author of "the Word about Igor's regiment" did it. The poem gradually, however, was forgotten, and only at the end of the 18 th century, after the discovery of the only surviving list, it began to sound with renewed vigor. (According To B. Rybakov)

The proposed set of tasks to the text is productive, since the language of the text is analyzed, which is one of the ways of developing, correcting and improving the communicative competence of students, as well as their language culture, since the text is a trace of culture in the language and language in the culture" [5].

\subsection{Different-style Sets of Texts for Analysis}

Besides this, work on formation of sets of texts of different styles was carried out. Each student received such a set. In addition to the individual tasks for each text, a general analysis plan, expressed in the following tasks and questions, for each text was attached:

- $\quad$ read the text and determine its style;

- determine the topic, the main idea of the text, giving your opinion; 
- identify the purpose of the author's statement (communication, exchange of thoughts, announcement, transmission of scientific information, etc.);

- $\quad$ specify the sphere of application (everyday life, textbook, article in the media, etc.);

- write down the language means (lexicalphraseological, morphological, syntactic) that are characteristic of this style;

- define the type of complex sentences connection (compositional, subordinate, asyndetic);

- specify compound sentences, determine their stylistic role in this text;

- identify the compositional conjunctions and determine their stylistic function;

- transform compound sentences into simple, complex sentences, and asyndetic sentences. Is such transformation always possible?

- compare the result of the synonymous substitution with the source text;

- what types of syntactic constructions (simple, compound - conjunction and non- conjunction) are stylistically justified?

As a result of working with a set of texts, students draw the following conclusions:

Compound sentences have their own semantic and grammatical features associated with the presence or absence of a conjunction, the meaning of the conjunction, the order of the parts, intonation, they are the most transparent in their structure, they are closest to simple sentences.

Compound sentences that are structurally simple can be contrasted with complex sentences, which are often characterized by structural complexity.

Unlike simple sentences, compound sentences are the most informative, which allows artists to use these constructions in an interesting, original, and sometimes unexpected way to create bright, expressive works, and help writers express their feelings more accurately, fully, and emotionally.

Compound sentences, both in the journalistic style and in the artistic description, narration (to strengthen the connection between pictures, facts, feelings) are used to describe facts, the results of observation, which gives smoothness, slowness, musicality to speech.
The compositional connection in a compound sentence can express different semantic relations, which allows to use these constructions in artistic speech: a) with the conjunction and (expresses a variety of shades of meanings) - simultaneity and sequence of actions, opposition, cause, condition, equality; b) the conjunctions and, but can form a stylistic antithesis, which enhances the expressiveness of speech, contrasts images, states, concepts; c) repeated conjunctions give sentences a special intonation, allow to highlight the details, the unity of the enumeration, show the breadth of the description, its incompleteness.

\subsection{Creative Tasks as the Most Productive Method in the Model of Experimental Teaching}

Thus, the students came to the conclusion that compound sentences are used in all functional styles:

- in scientific and official business styles, compound sentences are more widely used; in conversational and artistic styles, all types of compound sentences are used, while the role of compound sentences, as a rule, is more noticeable in them;

- the ratio of compound and complex sentences in the artistic style largely depends on the individual style of the writer, since in artistic speech compound sentences are used most often for the figurative representation of reality and for the transmission of the author's emotional assessment. This style is characterized by figurative and emotional-evaluative sentences;

- in the scientific style informative compound sentences are used;

- in the journalistic style, which is characterized by the impact function and the informative function, both informational and emotional-evaluative compound sentences are used. Journalistic style is also characterized by statements that express the will of the public;

- in the colloquial style compound sentences are used, usually small in size, transparent in structure, both informational and emotional-evaluative in nature. They are characterized by colloquial words, particles, interjections, conjunctions with colloquial coloring (and, but, but also);

- compound sentences, acting as synonyms for simple independent sentences, differ 
stylistically in that the thoughts in a compound sentence form a compound unit. Thus, in the artistic style, simple sentences highlight individual details in the picture depicted, and compound sentences combine the details into a more complete picture, revealing the relationship between them.

\subsection{Stylistic Design of Compound Sentences}

After completing these tasks aimed at understanding the role of compound sentences in texts of various speech styles, we propose the following exercises that help students develop stylistic construction skills.

- $\quad$ Exercise 1

Combine the sentences given below in pairs into one, using the most appropriate syntactic construction characteristic of the indicated style of speech. Place punctuation marks.

\section{- $\quad$ Exercise 2}

In the given text, replace, where possible, compound sentences by complex sentences, placing the appropriate punctuation marks. Which constructions give more conciseness to the information? Retell the text.

Creative tasks turned out to be the most productive for the formation of skills of free use of compound sentences in students' speech, since their feature is the organization of creative activities focused on cognition, creation, transformation and use of phenomena, objects of material and spiritual culture in new situations in the process of educational activities organized in cooperation with the teacher [6].

To form the skills and abilities to use compound sentences in texts of various speech styles, we used the following creative tasks:

- 1. Write an application (about transferring you to another class, about a new job), an application for visiting the exhibition, a power of attorney to receive books for the library from the store. Note the signs of official business style in the documents. Analyze the structure of the sentences and make a conclusion.

- 2. Make a description of one of the students in your class (for example, to the admissions office of an educational institution, to the military enlistment office, to the police, etc.).
- 3. Write a letter to your friend in colloquial style, paying attention to the main components of the letter. Think about the form and content of the letter.

- 4. Write a mini-essay of a journalistic nature in the genre of reasoning on one of the following topics: a) what I would like to be; b) what I would like to see in my friend.

- 5. Write an essay on the topic "Take care of your honor from a young age". Think about what type of speech will prevail in the composition.

- 6. Write an essay about a person you know well. Come up with a name that reflects the main idea.

- 7. Write about yourself by choosing one of the following options:

a) in the form of a diary (about your dreams and life plans);

b) about yourself in the third person - as you are seen by your friends, or family, or teachers.

c) in a fairy-tale form: events, actions are fictional, and the features, thoughts of the main character are yours.

- 8. Listen carefully to the oral speech of the teacher whose explanations you particularly like, to the speeches of the TV or radio announcers. Answer, what do you think is the secret of the impact of their speech on the audience?

- 9. Make microtexts (2-3 sentences each), in which it would be appropriate to use conjunctions that are characteristic of the colloquial style (and, and not that, not that...).

- 10. Write out from the explanatory dictionary of the Russian language at least 5 words and expressions with the stylistic mark colloq. and make compound sentences with them. Compare your texts.

- 11. Try, using the expressive means of artistic speech, to write a short funny story on the topic "An interesting case".

After this work, students receive the following homework assignments.

- 1 . Find in the newspaper the text with the compound sentences with borrowed words that can be replaced by common Russian ones. Edit the text.

- 2. Answer the following questions in writing. 
- What role does music play in your life?

- Do you agree with the statement that "without knowing the past, you cannot love the present, think about the future?

- Tell us about the street of your childhood.

- Tell us about one of the folk crafts you know.

- How do you understand the words "the spark of God in art?»

- Tell us about any case in the life of animals that you have witnessed.

- What character traits do you think a teacher should have?

- 3. Write an essay on the topic "Beauty and prettiness".

\subsection{Situational Speech Tasks as an Effective Method of Formation of Steady Communication Abilities}

Situational-speech exercises were conducted at the final stage of experimental training. To create natural communication situations, we used the form of discussion.

The purpose of the thematic discussion is to foster a culture of speech communication among students. The educational objectives of the discussion are to update the previously acquired knowledge, skills and abilities in the use of compound sentences by transferring them to natural communication situations. The use of discussion in natural communication situations has shown that it is most effective both for the transmission of information and for the consolidation of information, creative understanding of the studied material and the formation of value orientations.

To create a discussion in communication, we used texts containing an assessment of life phenomena, which allowed us to actively involve students in the discussion. All students expressed their attitude to the problems raised by the authors, and there were also those who disagreed with the position of the authors. As a result of the naturally created situation of communication, each high school student had the opportunity to express his opinion, tried to defend it, and discuss an actual problem.

\section{CONCLUSION}

Having proposed a methodological system of tasks for the formation of skills for using compound sentences, we confirm that "success in learning largely depends on how and on the basis of which speech units the transmission and reception of information is organized" [7]. A compound sentence is an important communicative unit in the speech of Russian language learners.

Thus, the system of exercises developed by us for the development of students' speech skills in the study of compound sentences included various types of exercises and tasks, gradually introduced in Russian language classes with bilingual students. We believe that the tested system has activated the speech activity of bilinguals, allowed them to consolidate their theoretical knowledge of compound sentences, corrected and developed their communication skills in Russian.

\section{AUTHORS' CONTRIBUTION}

Tskhovrebov A. S. is responsible for the design of a methodological model, preparation and conduct of experimental training of students, interpretation of the results obtained. Magomedova T. I. is responsible for scientific management of the research; formulation of scientific hypotheses tested by experiments, analytical generalization of the results obtained.

\section{REFERENCES}

[1] Vanyagina M. R., Pataraya E. S. Povyshenie motivatsii pri obuchenii inostrannomu yazyku [Increasing motivation in teaching a foreign language]. Novoe $\mathrm{v}$ lingvistike $\mathrm{i}$ metodike uchadeniya inostrannykh i russian yazykov [New in linguistics and methods of teaching foreign and Russian languages].

[2] Magomedova T. I. Russian-speaking professional communicative competence of students of the legal profile: model and technologies of formation in the conditions of multilingualism. - Makhachala: DSU, 2009. $232 \mathrm{p}$.

[3] Passov E. I. Program-concept of communicative foreign language education. M.: Prosveshchenie, 2000 - - 172 p.

[4] Koryakovtseva N. F. Modern methods of organizing independent work of foreign 
language learners: A manual for teachers. Moscow: ARKTI, 2002. - 176 p.

[5] Medynskaya V. L. The role of linguistic analysis of the text in teaching foreign military personnel the Russian language // Actual problems of linguistics and methods. - M., 2010. - p. 111-114.

[6] Tskhovrebov A. S. Model of formation and development of Russian-language professional communicative competence of foreign cadets of engineering and technical profile (syntactic aspect): Monograph. - St. Petersburg: VAMTO, LLC "R-KOPI", 2018. - 148 p.

[7] Ablam S. B. Intensification of teaching foreign language oral speech in school (V-VIII classes). - Minsk: Vysheysh. shkola, 1974. $144 \mathrm{p}$. 